\title{
浅谈中小制造企业 PDM 的实施
}

\section{Discussion on the Implementation of PDM in Small and Medium Manufacturing Enterprises \\ 王鹏}

Peng Wang

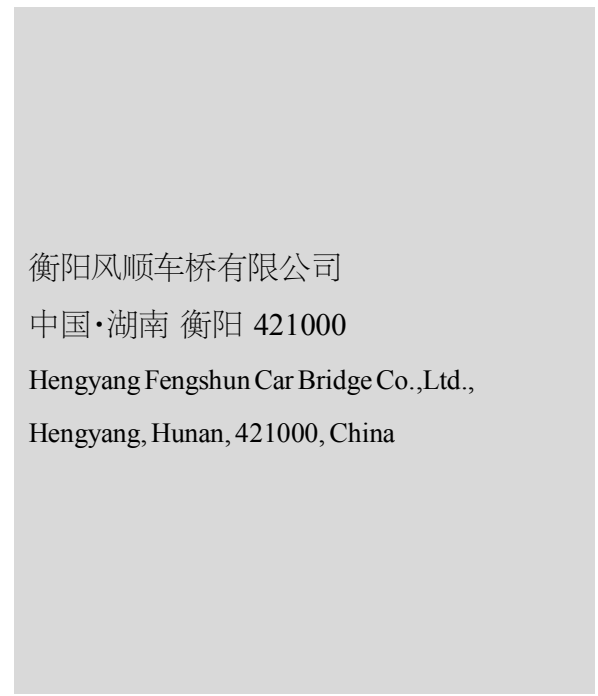

【摘 要】PDM 是一项管理所有与产品相关信息的技术。其核心在于能够使企业运行的所 有产品数据得以高度集成、协调、共享, 产品研发过程得以高度优化或者重组, 以便实现产 品全生命周期的信息管理,协调控制工作流程和项目进展。文章对中小制造企业实施 PDM 进行了探讨。

【Abstract】PDM is a technology that manages all product-related information. Its core is to enable all product data running by the company to be highly integrated, coordinated, and shared, and the product development process can be highly optimized or reorganized in order to achieve product life cycle information management and coordinate the control of work processes and project progress. This paper discusses the implementation of PDM in small and medium-sized manufacturing enterprises.

【关键词】中小制造企业; 系统; 实施应用

【Keywords】small and medium-sized manufacturing enterprises; system; implementation of application

【DOI】10.36012/etr.v1i4.714

\section{1 中小制造企业实施 PDM 的重要性和必}

\section{要性}

目前, 许多中小制造企业普遍存在一些亟待解决的问题: 第一, 许多中小企业采用了 $\mathrm{CAD} / \mathrm{CAPP} / \mathrm{CAM}$ 等先进的计算机 辅助工具, 产生了大量的电子文档, 这些电子文档在设计生产 中不断被查询、调用和更改, 存在版本混乱、容易丢失等问题 ${ }^{[1]}$, 严重影响了设计效率,企业的电子文档的管理问题亟待解决; 第二, 很多中小企业自身产品品种多, 系列化和小批量生产, 设计部门需要参考以前设计, 避免重复设计 ${ }^{[2]}$

企业实施 PDM 的重要性体现在以下几方面:第一,它能
够帮助企业产品数据由纸质管理模式转变为电子数据管理。 第二, 企业的技术文档安全大幅提高, 产品设计的追溯也能轻 松自如 ${ }^{[3]}$ 。第三, 项目管理与生产管理成本降低的同时,缩短 了产品面世时间。第四,实现各部门之间信息共享 ${ }^{[4]}$ 。销售部 能去争取新的客户; 采购部能高效地完成采购和外协; 财务核 算部门能通过系统生成的各种报表准确得出设备成本; 仓库 管理能及时统计库存量等。

\section{2 中小制造企业 PDM 的实施原则}

PDM 是企业信息加工的软件平台 ${ }^{[5]}$,管理企业产品数据 和企业人员。在实施 PDM 的过程中, 人们必须要有针对性 ${ }^{[6]}$, 


\section{实验与研究 Experiments and Research}

针对企业目前存在的问题、资金和技术能力,围绕企业发展规 划和目标来实施。同时,要选择合适的软件厂商, 制定可行的 方案, 先从部分应用着手, 然后分阶段制定目标, 逐步地推广。 其实施可分为 3 个阶段:原型、初样、推广。企业要实现 $\mathrm{CAD} /$ PDM 的系统集成,留下与 CAE/ERP/CRM/SCM 的接口,从而 奠定企业内部信息长期、有序建设的基础。

成熟的 PDM 厂商都有自己的设计理念, 所以, 企业一定 要仔细煁酌厂商的设计理念, 才能选择适合自身的设计理念, 并尽快融合 ${ }^{[7]}$ 。在选择产品和合作伙伴的问题上, 要根据企业 自身的需求和实力来决定。

\section{3 确立实施目标}

PDM 是实现企业优化管理的有效方法之一,是科学管理 与企业现实结合的产物 ${ }^{[8]}$ 。根据企业的实际情况, 实施 PDM 的 目标如下:第一, 电子数据存取, 建立适合企业本身特点的电 子信息平台。企业应着重于发展技术与工程数据( 设计/工艺 数据)方面, 因为这部分数据是最为复杂且使用频繁的关键源 头数据。第二,设计检索和公用信息检索。产品数据手工管理 阶段的信息检索和借阅程序复杂, 共享性差, 资料竞争使用, 严重影响了产品设计过程的效率与准确性。数据查阅是企业 实施 PDM 的基础,应支持工程设计中的信息检索与复用 ${ }^{[9]}$ 。第 三,工作过程实现流程电子化并且记录数据变更过程。企业要 完成工作进程管控, 就必须规范管理,任何人都必须接受这样 的管理,才能发挥应有的作用。

\section{4 中小制造企业在实施 PDM 系统时需要 解决的问题}

对于一个企业来说, 数据就是企业的核心竞争力,也是一 个企业的软实力 ${ }^{[10]}$ 。特别对于制造企业来说, 数据是根本, 用 好 PDM 系统, 是制造企业发展任务的重中之重。实施 PDM 是 企业的全体行为, 企业的领导要意识到 PDM 系统的重要性, 下决心将其运用,这是成功施行的保证。此外,还要注意解决 以下几个问题。

(1)电子化产品设计没有全面覆盖。很多企业留底备查很 多原始设计图纸,但是,随着电子信息化的普及,设计部门在 设计过程中还是靠查阅纸质图纸来进行改型设计。

(2)企业对电子数据不重视。有些企业通常对已经打印的图 纸进行归档,对计算机的电子版图纸却不要求统一归档保存。

(3)企业电子数据管理制度不完善。例如, 同一种数据由几 个部门同时管理维护, 这样就造成责任不明, 甚至造成数据流
向混乱。

(4)企业技术实力桪弱,缺少专业人才维护计算机数据。

(5)缺少有技术支持能力的软件合作厂商。PDM 是集计算 机网络、数据库、集成与开发等一体的系统, 需要企业与电脑 公司和软件企业联合运作 ${ }^{[1]}$ 。

\section{5 实施步骤}

(1)建立项目开发小组;

(2)进行网络建设;

(3)建立企业编码标准;

(4)搜集产品信息,建立技术数据库;

(5)对纸质数据进行数字化录用, 同时, 对相关数据进行分 析和建模;

(6)企业变更管理应落实在变更通知单的生成和管理；

(7)企业员工应进行培训。

通过一步步完成以上步骤后, 企业要先试运行各子系统, 得到验证后方能在本企业推广使用。

\section{参考文献}

[1]朱洪二.企业如何实施 PDM[J].建设机械技术与管理,2002(8): 38-39.

[2]张利强.中小制造企业 PDM 系统的开发 $[\mathrm{J}] . \mathrm{CAD} / \mathrm{CAM}$ 与制造 业信息化,2003(8):98-99.

[3]陈绍听.中小制造型企业精益生产实施策略及运用实践借鉴一 以 A 公司为例[J].财会学习,2019(15):216-217.

[4]范铁军,吴秀婷,施灿涛.中小钢铁企业智能制造实施路径研究 [J].冶金经济与管理,2018(1):8-11.

[5]刘晓丽.中国中小制造企业的用户决策型众包及实施路径研 究——基于创新和资源优化视角[J].燕山大学学报(哲学社会科学版), 2017,18(5):76-82.

[6]顾珂里.中小企业实施“互联网 + 制造”的认识和途径 [J].市场 论坛,2016(11):45-46+56.

[7]陈翰咏. 李克强: 深人实施《中国制造 2025》要对中小企业和 “双创”企业给予充分支持[J].中国应急管理,2017(5):16.

[8]刘海渔.中小企业绿色制造战略实施及其演化过程研究 [J].才 智,2015(30):308

[9]单悦,初凤荣.中小制造企业实施作业成本法问题研究 [J].中外 企业家,2015(11):69-70.

[10]柳丽,祝成.中小企业实施敏捷制造的模式探讨 [J].中国制造 业信息化,2005(8):131-133+136。

$[11]$ 韩渝辉,王憝华.中小制造企业实施 ERP 的模型研究 [J].价值 工程,2006(11):81-83. 